\title{
A Guide for Increasing Scholarship for Medical Educators
}

\author{
Donna M. Windish, MD, MPH', , Shobhina G. Chheda, MD, MPH', \\ Steven A. Haist, MD, MS ${ }^{4}$, and Eva M. Aagaard, MD ${ }^{5}$
}

${ }^{7}$ Yale University School of Medicine, New Haven, CT, USA; ${ }^{2}$ Yale Primary Care Residency Program, New Haven, CT, USA; ${ }^{3}$ University of Wisconsin School of Medicine and Public Health, Madison, WI, USA; ${ }^{4}$ University of Kentucky College of Medicine, Lexington, KY, USA; ${ }^{5}$ Washington University School of Medicine, St. Louis, MO, USA.

\begin{abstract}
Disseminating scholarly work as a clinician educator is critical to furthering new knowledge in medical education, creating an evidence base for new practices, and increasing the likelihood of promotion. Knowing how to initiate scholarship and develop habits to support it, however, may not be clear. This perspective is designed to help readers choose and narrow their focus of scholarly interest, garner mentors, find potential project funding, and identify outside support through involvement with national organizations, collaborators, and faculty development programs. By incorporating these suggestions into their daily work, educators can find ways to connect their clinical and educational interests and make their daily work count toward scholarship.
\end{abstract}

KEY WORDS: medical education; scholarship; faculty development.

J Gen Intern Med 34(7):1348-51

DOI: $10.1007 / \mathrm{s} 11606-019-04948-1$

(C) Society of General Internal Medicine 2019

\section{INTRODUCTION}

The first step towards success in any occupation is to be interested in it.

- William Osler

Being scholarly in medical education fulfills our intellectual curiosity, feeds our desire to contribute to the field, inspires others to pursue educational initiatives, and helps to meet the requirements for advancement in our careers. While promotion criteria for clinician educators differ between institutions, producing scholarship is often a key determinate to academic advancement. ${ }^{1}$ The value of educational scholarship is increasing and garnering support. ${ }^{2}$ Some institutions have developed academies of medical educators ${ }^{3}$ while others have created education scholarship units. ${ }^{4}$ Recently, a survey of general internal medicine division directors demonstrated that directors find a wide variety of scholarly work done by

Prior Presentations: Presented as a workshop for the 2016 Society of General Internal Medicine TEACH (Teaching Educators Across the Continuum of Healthcare) Program at the National SGIM meeting in Hollywood, Elorida

Published online April 16, 2019 clinician educators to be important. ${ }^{5}$ Despite these advances, educators often lack the time, ${ }^{6}$ resources, skills, or financial support $^{5,7}$ to successfully complete scholarly work.

Success in educational scholarship is possible for you if you adopt some best practices. Important factors include developing a unique line of scholarship, ${ }^{8}$ surrounding yourself with like-minded people who can provide honest support and mentoring, ${ }^{9}$ scheduling time for scholarship without letting competing interests take over, ${ }^{10}$ and publishing your work. This perspective will expand on these factors and provide you with other practical suggestions to help you develop these best practices into scholarly success.

\section{DEVELOP A NICHE}

Medical education is a broad field and finding a place to start scholarship can feel overwhelming. This is where developing a "niche" is helpful. Several strategies can be used to find a niche. Consider all your activities including clinical work, teaching, research, education, and administration, and then consider where these activities intersect. How do these activities coincide with what you most enjoy? Another strategy for identifying a niche is to note what other medical educators are working on at your institution or potential collaborators at other institutions and then find where your work can extend or complement their work. Make sure you find an area that can be uniquely or collaboratively yours, not one that is already oversubscribed. Once you define a niche, assess your likelihood of success by asking your mentors. Be sure your niche brings value to your division, department, and institution and determine how your work aligns with your institution's promotion criteria. ${ }^{1}$

Once you have chosen a niche, become an expert in it. Begin by reading and mastering the literature related to your focus. Using a systematic approach to the literature review will allow you to define the gaps within your niche for you to fill. It also allows you to write and submit a review article in your area of developing expertise. As you develop your expertise, consider volunteering to review abstracts for professional society meetings or offering to work with a senior mentor to review for a journal. Make sure the categories you request to appraise align with your interests and goals and incorporate practices from references that describe how to be a reviewer. $^{11,12}$ 


\section{LEARN ABOUT FACULTY DEVELOPMENT OPPORTUNITIES}

Consider formal training or seek out resources to increase your knowledge or skills. Become familiar with resources at your institution and through medical organizations that can help you gain the skills to generate and disseminate your scholarly work. Some institutions offer a Teaching Scholars Program or fellowships and in-person or online master's programs. Research centers at medical schools may provide courses that a medical educator might find helpful in developing specific research skills. Organizations, such as the AAMC, offer programs to help attendees gain the knowledge and skills to conduct medical education research including the Medical Education Research Certificate (MERC) program includes workshops that focus on important educational research topics. $^{12}$

\section{APPLY SCHOLARSHIP TO CURRICULUM DEVELOPMENT AND TEACHING}

Think of ways to translate your educational activities into scholarship by envisioning a priori any research-related questions that you could pursue. Collecting results around individual learners, the program, and, if possible, patients will demonstrate the success of your initiative and is more likely to result in recognition and publication. Improve the success of your evaluation by having a similar comparison group and meaningful assessment measurements of your outcomes. Several suggestions exist to strengthen the quantitative research methods in medical education. ${ }^{13}$ Consider using Bloom's taxonomy ${ }^{14}$ to determine the highest level of cognitive objectives to measure and Miller's pyramid ${ }^{15}$ to assess the highest level of learners' skills to assess. Remember to align program and learner goals with learning activities.

As education research protocols differ from those in traditional research, navigating your Institution Review Board's (IRB) policies for educational scholarship may be a challenge. ${ }^{16}$ Thus, for each educational project, reach out to your IRB before initiating your work to ensure appropriate review is obtained.

\section{IDENTIFY A TEAM OF MENTORS}

Mentors are critical to career success. Effective mentorship results in faculty who are more scholarly, promoted more quickly, and more likely to stay at their academic institution. ${ }^{17-19}$ Faculty with mentors are also more likely to be satisfied with the distribution of their work and report higher self-efficacy than their peers without mentors. ${ }^{9}$ Unfortunately, finding mentors may be more difficult for clinician educators, ${ }^{9}, 20,21$ This may reflect a lack of senior mentors who have been promoted as clinician educators, competing time pressures, and less formal mentoring structures.
Since there is no perfect mentor, search for multiple individuals whom you respect in your area of interest and reach out to them. Assess these individuals' communication and interpersonal skills, your ability to form a personal connection, and your sense of shared values. ${ }^{22}$ Some of these relationships will evolve over time into traditional mentor relationships, while other individuals may become coaches, sponsors, or connectors. ${ }^{23}$ If possible, find a single guiding mentor whom you can meet with at least monthly to help review your career trajectory, provide feedback on your scholarship, work on time management, and keep you accountable for your work. Be honest in your relationship and tell the mentor what you need in a mentor relationship. ${ }^{8}$ Additionally, consider peer mentorship where individuals at a similar career level meet regularly to mentor and support each other. ${ }^{24}$ Peer mentoring can increase job satisfaction, a sense of belonging to a supportive community, scholarly productivity, and perceived improvements in career advancement. ${ }^{25-29}$

\section{IDENTIFY COLLABORATORS LOCALLY AND FROM OTHER INSTITUTIONS}

Performing a study on one's own is a daunting and ill-advised endeavor, so an early step in the journey is to find collaborators. Collaborators may share an interest in your niche or bring unique skills that will help you move your work forward. Sometimes you may find individuals locally who share your interest. Frequently, you need to look outside of your institution. Look for professional meetings that focus on your niche or attend sessions and interest groups within conferences that have this focus. In these settings, make it a goal to meet other medical educators and come home with names of contacts with whom you will follow up. Consider reaching out to those who have published in your area of interest. These authors are often interested in collaborating with those wanting to take the next related step within their field of work. When you find collaborators, consider engaging in multi-institutional projects which can allow you to gain important skills, develop life-long collaborations, and can increase your study's power and generalizability making it more likely to be published.

Often medical educators who do research need collaborators with expertise in survey design, statistical analysis, or measurement of patient outcomes since few clinician educators have had extensive research training. Departmental or school research programs or biostatistical units, including clinical and translational science units, may be able to provide access to such individuals.

A key component in maintaining relationships with collaborators is committing to transparency. It is wise to address authorship on scholarly products, including presentations and publications in the beginning, to help prevent misunderstanding and conflict down the road. ${ }^{30}$ Principles to follow in making these decisions have been articulated elsewhere. ${ }^{31}$ 


\section{SCHEDULE TIME FOR SCHOLARSHIP}

Once you have made the commitment to scholarship, prioritize that time and do not allow other "urgent" but less important tasks to take precedent. ${ }^{10}$ Schedule this time in your calendar each week. Three to four hours at a time should be sufficient, but even smaller increments can work. Learn to say no to unnecessary meetings and service obligations. Engage your mentors if you are unsure which obligations are acceptable for you to avoid. Consider spending your scholarly time in an area where you are unlikely to be interrupted. Do not open your email during your scheduled scholarship time and turn off email alerts. Finally, set deadlines for yourself and keep them.

\section{GET INVOLVED IN NATIONAL ORGANIZATIONS}

Professional organizations represent a collection of individuals who are working toward a common goal of promoting and improving the medical profession. They provide resources, education, information, opportunities, and, most importantly, peers, collaborators, and colleagues with similar interests. ${ }^{32}$ National organizations allow you to present your work, network, learn what others are doing, and re-energize and motivate you to achieve in your areas of interest. Several organizations specifically focus on academic medicine and careers in health professions education. A few examples include the Alliance for Academic Internal Medicine (AAIM), the Society of General Internal Medicine (SGIM), the Society of Hospital Medicine (SHM), the Association for Medical Education in Europe (AMEE), and the Association of American Medical Colleges (AAMC). Talk to mentors and peers about which organizations they belong to and why, explore websites, and attend regional and national meetings to get a feel for the priorities of the organization. Once you have identified a potential professional home, get involved. Volunteer for a committee or task force. Choose things that align with your interests. As your career evolves, consider leadership opportunities. This type of engagement not only leads to excellent collaborations for scholarship but also can help support you in your promotion process.

\section{IDENTIFY OPPORTUNITIES FOR SCHOLARSHIP FUNDING}

While medical education research is underfunded, ${ }^{5,7,33}$ opportunities for funding are available. ${ }^{34}$ Start small and seek counsel from clinician educators who are or have been funded in the past. Medical schools, hospitals, and university departments may have small grant programs for new or junior faculty. Small grants provide opportunities to generate pilot data before applying to larger granting agencies. Some specialty organizations can provide grants for medical education research. ${ }^{35}$ The Stemmler Fund from the National Board of Medical Examiners award grants related to innovations in assessment. ${ }^{36}$ Nonprofit foundations such as the Robert Wood Johnson Foundation ${ }^{37}$ and the Josiah Macy Jr. Foundation ${ }^{38}$ fund innovations in medical education.

\section{DISSEMINATE YOUR WORK}

Today, opportunities to disseminate medical education scholarship at various stages of a project are extensive. Regional and national meetings provide excellent initial venues to disseminate educational scholarship in the form of an oral abstract or poster. However, one of the most common pitfalls is to stop dissemination after this step. Many good ideas are presented at academic meetings but never make it to press. ${ }^{39}$ Avoid this by having the colleagues you have met during your presentation spur notes for the "Discussion" section of a paper. This is when devoting time and discipline to writing is most important. Remember, getting started is often the hardest part of writing so pick an area of the paper that you are most familiar with and begin there. ${ }^{40}$ For many people, that would be the "Methods" or "Introduction" section. Know that getting any words on paper is the only way to start gaining momentum and that it takes many iterations before what you write will be ready to submit for publication. Note, part of the fun of writing is working with other members of your mentoring and collaborating team who can help take your very rough initial draft and convert it to a polished final product. $^{40}$

Manuscripts, oral abstracts, book chapters, curricular descriptions, simulations, and web-based tutorials are just some of the different formats for presenting one's scholarship. ${ }^{41}$ Many journals publish peer-reviewed medical education scholarship including the Journal of General Internal Medicine. The AAMC's MedEdPORTAL offers an online peerreviewed venue to publish as well.

\section{SUMMARY}

Scholarship in medical education is a fulfilling and worthwhile pursuit. By exploring areas where what you do intersects with what your greatest interests are, you can begin to identify your niche. Be complete in your literature review to avoid unknowingly studying what is already known. Work to find a mentor or mentors with whom you connect and whom can guide you away from pitfalls. Get help from your division head, department chair, national organizations, and colleagues if you are struggling to find someone to serve in this critical role. Avoid letting clinical or other administrative work creep into your scholarly time. Doing so will cause you to lose momentum and not allow you to follow through on your scholarship goals. ${ }^{42}$ do not forget to give yourself the academic credit you deserve toward promotion by turning your scholarly posters and meeting abstracts into peer-reviewed publications. Finally, find enjoyment in what you do, as scholarship can be 
an important and rewarding part of your personal and professsional life.

Corresponding Author: Donna M. Windish, MD, MPH; Yale Primary Care Residency Program, 1450 Chapel Street, Private 304, New Haven, CT 06511, USA (e-mail: donna.windish@yale.edu).

\section{Compliance with Ethical Standards:}

Conflict of Interest: The authors declare that they do not have a conflict of interest.

\section{REFERENCES}

1. Atasoylu AA, Wright SM, Beasley BW, et al. Promotion criteria for clinician educators. J Gen Intern Med 2003;18(8):711-6.

2. Irby DM, O'Sullivan PS. Developing and rewarding teachers as educators and scholars: remarkable progress and daunting challenges. Med Educ 2018;52:58-67.

3. Searle NS, Thompson BM, Friedland JA, Lomax JW, Drutz JE, Coburn M, Nelson EA. The prevalence and practice of academies of medical educators: a survey of U.S. medical schools. Acad Med 2010;85(1):48-56.

4. Varpio L, O'Brien B, Hu W, Ten Cate O, Durning SJ, van der Vleuten C Gruppen L, Irby DM, Humphrey-Murto S, Hamstra SJ, Hu W. Exploring the institutional logics of health professions education scholarship units. Med Educ 2017;51(7):755-67.

5. Yeh HC, Bertram A, Brancati FL, Cofrancesco J Jr. Perceptions of division directors in general internal medicine about the importance of and support for scholarly work done by clinician-educators. Acad Med 2015;90(2):203-8.

6. Zibrowski EM, Weston WW, Goldszmidt MA. 'I don't have time': issues of fragmentation, prioritization and motivation for education scholarship among medical faculty. Med Educ 2008;42(9):872-8.

7. Reed DA, Kern DE, Levine RB, Wright SM. Costs and funding for published medical education research. JAMA 2002; 294 (9):1052-57.

8. Detsky AS, Baerlocher MO. Academic mentoring-how to give it and how to get it. JAMA 2007;297(19):2134-6.

9. Feldman MD, Arean PA, Marshall SJ, Lovett M, O'Sullivan P. Does mentoring matter: results from a survey of faculty mentees at a large health sciences university. Med Educ Online 2010;15. doi: https://doi org/10.3402/meo.v15i0.5063.

10. Lowenstein SR. Tuesdays to write ... A guide to time management in academic emergency medicine. Acad Emerg Med 2009; 16(2):165-7.

11. Spigt M, Arts IC. How to review a manuscript. J Clin Epidemiol 2010;63(12):1385-90.

12. Vogt HB, Huber VC, Hansen KA. So you want to be a reviewer. S D Med 2017;70(3):127-133.

13. Sullivan GM. Getting off the "Gold Standard": randomized controlled trials and education research. J Grad Med Educ 2011; 3(3): 285-9.

14. Adams NE. Bloom's taxonomy of cognitive learning objectives. J Med Libr Assoc 2015; 103(3): 152-3.

15. Norcini JJ. Work based assessment. BMJ 2003 ;326(7392):753-5.

16. Dyrbye LN, Thomas MR, Papp KK, Durning SJ. Clinician educators experiences with institutional review boards: results of a national survey. Acad Med 2008;83(6):590-5.

17. Sambunjak D, Straus SE, Marusic A. Mentoring in academic medicine: a systematic review. JAMA 2006;296:1103-15.

18. Sambunjak D, Straus SE, Marusic A. A systematic review of qualitative research on the meaning and characteristics of mentoring in academic medicine. J Gen Intern Med 2010;25:72-8.

19. Straus SE, Straus C, Tzanetos $\mathbf{K}$, International Campaign to Revitalise Academic Medicine. Career choice in academic medicine: systematic review. J Gen Intern Med 2006;21:1222-9.

20. Chew LD, Watanabe JM, Buchwald D, Lessler DS. Junior faculty's perspectives on mentoring. Acad Med 2003;78(6):652.
21. Wasserstein AG, Guistberg DA, Shea JA. Mentoring at the University of Pennsylvania: results of a faculty survey. $\mathrm{J}$ Gen Intern Med 2007;22(2):210-4.

22. Straus SE, Johnson MO, Marquez C, Feldman MD. Characteristics of successful and failed mentoring relationships: a qualitative study across two academic health centers. Acad Med 2013:88(1):82-9.

23. Chopra V, Arora VM, Saint S. Will you be my mentor?-Four archetypes to help mentees succeed in academic medicine. JAMA Intern Med 2018;178(2):175-176.

24. Humphrey HJ. American College of Physicians. Mentoring in Academic Medicine. Philadelphia: American College of Physicians, 2010.

25. Bussey-Jones $\mathbf{J}$, Bernstein $\mathbf{L}$, Higgins $\mathbf{S}$, et al. Repaving the road to academic success: the IMeRGE approach to peer mentoring. Acad Med 2006;81:674-9.

26. Files JA, Blair JE, Mayer AP, Ko MG. Facilitated peer mentorship: a pilot program for academic advancement of female medical faculty. J Women's Health (Larchmt) 2008;17(6):1009-15.

27. Pololi LH, Knight SM, Dennis K, Frankel RM. Helping medical school faculty realize their dreams: an innovative, collaborative mentoring program. Acad Med 2002;77:377-84.

28. Santucci AK, Lingler JH, Schmidt KL, Nolan BAD, Thatcher D, Polk DE. Peer-mentored research development meeting: a model for successful peer mentoring among junior level researchers. Acad Psychiatry 2008:32(6):493-7.

29. Seritan AL, Bhangoo R, Garma S, Dube J, Park JH, Hales R. Society for women in academic psychiatry: a peer mentoring approach. Acad Psychiatry 2007;31:363-6.

30. Roberts, LW. Addressing authorship issues prospectively: a heuristic approach. Acad Med. 2017;92(2):143-6.

31. International Committee of Medical Journal Editors (ICMJE). Defining the role of authors and contributors. Available at: http://www.icmje.org/ recommendations/browse/roles-and-responsibilities/defining-the-roleof-authors-and-contributors.html. Accessed 16 Oct 2018.

32. HealtheCareers Network. Four benefits of joining your professional healthcare association. Available at: http://news.healthecareers.com/ 2015/03/the-benefits-of-joining-your-professional-healthcare-association/. Matthew Santomarco on Mar 3, 2015. Accessed 16 Oct 2018.

33. Carline JD. Funding medical education research: Opportunities and issues. Acad Med 2004; 79(10):918-24.

34. Academy of Medical Educators (AME). Funding sources for medical education research. Available at: http://www.kumc.edu/school-of-medicine/ame/resources/funding-sources-for-medical-education-research. html. Accessed 16 Oct 2018.

35. Emergency Medicine Foundation. Available at: https://www. emfoundation.org/. Accessed 16 Oct 2018.

36. Stemmler Fund, National Board of Medical Examiners Available at http://www.nbme.org/research/stemmler.html. Accessed 16 Oct 2018.

37. Robert Wood Johnson Foundation Grants and Grant Programs. Available at: https://www.rwjf.org/en/how-we-work/grants-and-grantprograms.html. October 16, 2018.

38. Josiah Macy Jr. Foundation. Available at: http://macyfoundation.org/ apply. Accessed 16 Oct 2018.

39. Coverdale JH, Roberts LW, Balon R, Beresin EV. Writing for academia: getting your research into print: AMEE Guide No. 74. Med Teach 2013;35(2):e926-34.

40. Egloff HM, West CP, Wang AT, Lowe KM, Edakkanambeth Varayil J, Beckman TJ, Sawatsky AP. Publication Rates of Abstracts Presented at the Society of General Internal Medicine Annual Meeting. J Gen Intern Med. 2017;30:673-678.

41. McGaghie wC. Scholarship, publication, and career advancement in health professions education: AMEE Guide No. 43. Med Teach 2009;31(7):574-90.

42. Gottlieb M, Dehon E, Jordan J, Bentley S, Ranney ML, Lee S, Khandelwal S. Santen SA. Getting published in medical education: overcoming barriers to scholarly production. West J Emerg Med 2018;19(1):1-6.

Publisher's Note Springer Nature remains neutral with regard to jurisdictional claims in published maps and institutional affiliations. 